\title{
Detection of Seeds in Citrus Using MRI under Motion Conditions and Improvement with Motion Correction
}

\author{
N. HERNANDEZ; P. BARREIRO, M. RUIZ-ALTISENT, I. RUIZ-CABELLO, \\ M. ENCARNACION FERNANDEZ-VALLE
}

Physical Properties Labonatory, E.T.S.I.A, Polytechnit University of Madrid, Spain Instltuto de Estudias Biofuntionales, Compintense Uriversity of Madrid, Madrid, Spain

Centro de Asistencia a la investigación de Resonancia Magnettien Nuctear.

Complutense university of Matidid. Madrid. Spation

\begin{abstract}
Magnetic resonance imaging (MRi) is studied under an online strategy. Axial FLASt images (780 ms acquisition tme) have been aralyzed to identify seed-containing oranges conveyeof at 50 and $100 \mathrm{~mm} / \mathrm{s}$ through a 4.7 Tesla spectrometer. Developed algorithms enthle an automated ldentfiotiton of oxanges with more then arte seed, though axial imonges under motion condiriests sufler from signifilcant bluming artifacts. To overcome this hindrance, coronal Flash intages hawe been acquifed (279 ms acquisition time). developing devoted algorithms for motion correction with encouraging results for quallty improverment of dynamic itnajes. 2005 whley Pentodicals. thic toncepts Magn Reson Pan B IMagn Reson Engineeringl 26as 000-000. 2005
\end{abstract}

KEY wORDS: MRI; orline; seeds; phase shift; motion cotrection

\section{INTRODUCTION}

The increabing internal quality detrtand far fruits and vegetables is driving thevelopreat of device are capatile of evaluating stitferent parameters itor

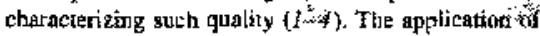
zondestructive techriquen under an ooline strategy (below I second/samples) is entotraged by the added value that con be actioved by the product. The capabitity of the nuclear magnetic resonance (NMR) of giving response to this challenge is relevant as stated
.... by several antwrs. Zion et al. $(5,6)$ investigated the real-time detection of pits in sterries by MR pryjec" tions as well as a fast, computerized detection of brujses in apples by MR indiges; Chen et al. (7) tenonstrated the feasibility of the FID spectum for the dymitnic evatuation of the totiurity stage in avocados; Barreino et al. (8) studied the prospects of the rapid detection of mealiness in apples by NMR rulaxometry; and Hermández et al. 9 i doveloped a procedure to delect freeze injury in oranges undet motion conditions by MR.

T'the presence of seeds, especially in mandarin oranges. involves a loss of quality that has i high itaput on the prices. This application requires reliable solutions trexause the size of seeds is a limiting factor. A precedent work developed by Blasco et ill. (IO) under static coxdicions confirmed the applicability of the MRl techniuyue for seed detection, although the acqu' sition time $(7 \mathrm{~s})$ needs to be shortened for corrumescial purposes. Th, reacth working velocities clost to the optimal ones, some premises arise ns necessary: (i) 
fruit should be imaged in continuous motion, (ii) the total sean time decrease should minimize the sensitivity to motion as well as to segregate fruit in quality categories, and (iii) the postprocessing algorithm for automatic characterization should be minimally timeconsuming.

Among these premises, the second one presents a major limitation as rapid acquisitions such as those using single-shot echo planar imaging require specialized hardware. Radial scan with projection reconstruction is an alternative to $2 \mathrm{D}$ Fourier reconstruction and can reduce motion-induced artifacts $(I l)$. Motion artifacts, which degrade the image, are one of the greatest problems to be solved. This kind of artifact appears because the imaged tissues do not remain in the same location during the time required for the acquisition. Motion can occur during RF pulses, between RF pulses, during sampling, and between phase-encoding steps (12). Phase shifts are generated in the acquired $k$-space that affects the outcome of the image reconstruction and are responsible for ghosting and/or blurring artifacts of the image. The former corresponds to a periodic motion with temporal variatioas between phase-encoding views (13), in a time scale about the recovery time (TR). The latter is a consequence of nonperiodic motions that take place at the time scale equal to or less than the echo time (TE). As the sample motion under online sorting is translational and nonperiodic, the blurring artifact is expected 10 appear in the MR images, which may oceur in any direction and is proportional to the displacement. It causes spatial mismapping of signal from the true location, which leads to a decrease in the edge definition and makes identification of the structures difficult (13). Several authors have proposed proctsdures to correct the motion effect. Some of them employ image-based methods $(14-18)$ applicable to conveying conditions where the motion characteris tics are extracted from the acquired images without additional information. A second group of researchers apply motion correction either from information previously known $(19)$ or extracted from additional acquisitions $(20)$. The present study develops a procedure that takes advantage of the two strategies, image based and motion based, to enhance the quality of MR images under motion conditions, allowing a reliable seed detection in citrus fruit.

\section{MATERIAL AND METHODS}

\section{Samples}

Experimental work was developed on oranges and lemons. Eleven oranges were obtained at a local mar-

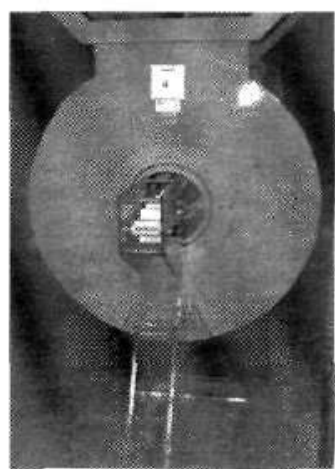

Figure 1 Bruker BlOSPEC $47 / 40$ and conveyor belt.

ket and eight lemons were picked from a local orchard. Samples were inspected by MRI before the experiments, identifying eight oranges and four lemons as seed-containing. and three oranges and four lemons as seedless. Samples were maintained as room temperature $\left(23^{\circ} \mathrm{C}\right)$ during measurements.

Two phantoms were used for reference purposes: a sphere filled with doped water (copper sulphate $1 \%$ $w / w)$ and a water-filled cube.

\section{MRI Equipment and MRI-Compatible Fruit Conveyor}

MRI experiments were performed on a Bruker BIOSPEC $47 / 40$ (Ettlingen, Germany) spectrometer operating at $200 \mathrm{MHz}$. The bore of the magnet is horizontal, $147 \mathrm{~cm}$ long and with a $40 \mathrm{~cm}$ diameter reduced to $26 \mathrm{~cm}$ when the gradients stack in place. A birdcage coil with an itner diameter of $20 \mathrm{~cm}$ was used.

To simulate an online inspection, a special prototype conveyor was designed and built to move the fruits through the spectrometer (see Fig. 1). An electronic device controls the stepper motor that conducts the belt and allows a variable speed drive and bidirectional motion as well as controls the signal acquisition triggering. An electro-optic device detects the fruit as it passes by and delivers a digital signal to the controller to synchronize the MRI signal acquisition with fruit shifts. More details can be found in a previous work $(9)$.

MRI Sequences. The phase shift problems arising from the acquisition under motion conditions were bore in mind to select a fast imaging sequence. Short acquistion time leads to a reduction in the displace- 
ment atd therefore to an improvement in the image quality, and so a last low angle shot (FI,ASH) pulse sequence was used.

The major physiological difference between jaicy Hest and solid-like seed tissue is the restriction in proton ration As such, with FLASH T2* ${ }^{*}$ wcighted innages, seed tissue appears bypointense, whereas ficsh tissue appears as bright pixels within the imsge. The FLASH T2*-weighted sequence parameters used for seed identification in oranges were set to enhance contrast tander the restriction of minimum acquisition time: recovery fime (TR) $12.2 \mathrm{~ms}$, who time (TE) 3.8 Ins, and flip angle 10 degrees. The field of view (FOV) and the slice thickness used were $12 \times 12 \mathrm{~cm}$ and $10 \mathrm{~mm}$. The stice thickness way selected to acquite signat from the region with the highest ptobability of seed presenoe. Images were collected with $128 \times 64$ and $128 \times 32$ acquisition matrix sizes with a total acquisition titne of $780 \mathrm{~ms}$ and $330 \mathrm{~ms}$ respec. tively. This innaging sequence will hereafter te called type 1.

One type I image was obtained from each orange at each rug of the belt; the number of sctavisitions for signal averaging was set to 1 . Threc repetitions per frut were performed to study the repeakability of the rackasurentents. All inages were zeto-filio iv $128 \times$ 128 points before being teennstructed. Images were digitized il 4 bytes. Puise gains, attenuator. and shimtwing settings were adjusced with the first sample (stelected is representutive of the whole se1) and were hedd constant alang the experiments.

Oranges used under type 1 images were placed in the belt with their centrul axis (uxig betwees the polex) along the : direstion to obtain axial images displaying the trankveryal section of the central axis within the middle of the FOV. Within this ogientation, sted-

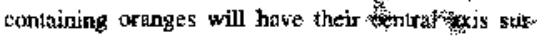

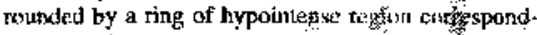
ing $t o$ seeds.

Synchronization of fait motion and triggering of sjgnal acquisition for type 1 images rakes it possible to locate within the FOV the equatorial area of the fruit while conveyed. This synchronizntion wass set for art orange with average dimensions so that slight FOV lacation variation may appear for the test of sampled ones.

For type 1 images, the FOV laid in the plane perpendicular to the motion ( $x y$ plane), axd superimposition of sigats from different slives due to truit motion led to image blumring.

To açuire signal from a single slice (no slices superimposition., the FOV bas to lie in the $x z$ plane: that is to say, wronal images are needed. However, this makes phase shift corraction insessary, which
Inay be applied to the k-space lines. This type of image will be called Fl.ASH type 2.

A ncw experiment was carried ant with lemons viewed with type 2 inuges in order to develop a procedure for phase shif correction. When imaging lemoss with type 2 images the acquisition parameters were those of the type 1 ones, with the exception of the FOV vicntatinn, and thus the acquisition times were hezd ( $780 \mathrm{~ms}$ and $390 \mathrm{~ms}$ for each aliquisition ryalrix size). Alf innger were zero filled to $128 \times 128$ Foints before being teconstructod. For type 2 inages, lernons wete placed with their certral axis along the $y$ maggnet axis. Putse gains, attenuthor, shimming settings, and FOV lociation were adjusied for a lemein with average dimeasions and were held constant.

Type I and type 2 wrere collected under stationtary conditions (reference inages) and with convey motion through the magnet at 50 and $100 \mathrm{~mm} / \mathrm{s}$ beit speeds.

\section{Image Processing and Data Analysis for Axial MR}

Automated Analysis of Orange Images for Seed De" tection. Online inspestion requires an axulubated datis andysis protecys thal allows unsupervised evaluation of the produst. Thus, an initial algorithon was developed using Matlab ('The MathWorks, Lne.) to extract severat mathextatical fealures (see below) from the magnitiste imizges for the characterization of extch sample. Those that best characterized tye presence of seexis were selected for fartber analysis. The algorithm exploits the fact that regions with seeds afe displayed as hypointense und it ix applied to static and dynumic MR images.

The tirst step in the algorither is to sutonatically sclect the region in interit (RoI) detioed as the frust porrion in which furthey processing is applied. The background pixelis and pext pixels, which bave sjgnal inteosity below an automatically iterative computed ujeshold, are not considered for further calculations. On each ikration, threstold intensity is increased and the pixels with signal vulues ahove the threstrold are idertifed as part of the ROI. The selected ROA comprises the muximotum area surrourded by identified pizels. The end of the iteraive process is achieved witenever stabilization in the ROl is reschert. Mare details can be fount in a previous work (9).

Once the ROI bas been obtained, the low intensity signal regions due to the presence of the central axis and the seeds (il the case) ane identifled. For twe segmentation of sucts zecions the contour Matiat function is used. The followirg features are calculated from the ROI and hypointelse signal region (IFIR): 
- numher of pixels theionging to the ROF,

- number of pixels belonging to the HIR:

- IfJR to ROI (seed to tissue) rato (STR);

- perineter of the HIR area (P) 10 extract geometrical information;

- tistances from the ceriats of gravity of the HIK to the perimeter points:

- the maximum radius valuc $\left(R_{\max }\right)$;

- the number of radif higher than the averaged maximum rudius of the seed fiec samples (NR > $\mathbf{R}_{\text {max }}$ ):

- the surn of the former radius values (NS $=$ $\mathbf{R}_{\text {max }}$;

- the nunber of radii higher that the averaged enean radius of the seed tree sangles $(\mathrm{NR}>$ $\left.\mathbf{R}_{\text {mean }}\right)$; and

- the sum of the lisrmer radii values (NS $>\mathrm{R}_{\text {mean }}$ ).

These feacures were corrclated at a significutce level of 0.05 to establish retations between them and toward the reference measurements. The features with the best correlarions were used to join the frutits and yn extract the inherent clusters in the studied sample. Cluster analysis was developed using STATISTic (StatSolt) according to the Euctidean distances and by applying the Ward's methond on mininize the sum of squares (SS) of the hypothetical clusters that con be formed at each step. The inspection sf the formed clasters allows assess to the diseriminaris capability of the used features and to eytablish the number of groups that can be differentiated by the number of seeds within their samples. Once the number of groups was establisbed, the mesn. the standerd deviation (SD) and the ratio betwen the averaged eror (Hveraged SD) and the mean range were obtained as reference measurements for the discrimination fse Fig. 2).

Metrology Merusuremeni of Orange Imagks. 'The autontatic seed detection procedure has th be consistent and accurate for retiable seed-containing frrviss discrimination. Therefore, a stuxiy of the repealability of the features extractes from the MR images wat performed.

Repeatability is a measure of the ability of a sensor to teachieve the same response tander simitar experimental conditions. It was assessed by takking three repetitions of each inage and by caiculating the av. erage of the standard deviations of confyuted features.

Appointment of Reference Measurements. Sumples: were cut in balf afier MRT for inspection. ROB images of the equatorial truit section were captured with

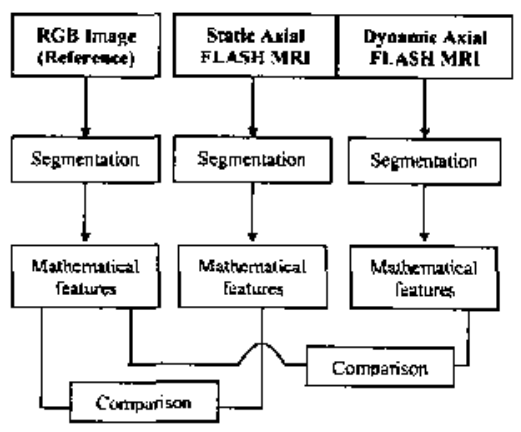

Figure 2 Summary of image prncessing and data analysis in axin] MR images (1,pe 1 inisges) for seed detection in oratuges.

a digital cumero and afterwards seeds onithith the im nged stice (10 mm thick) were counted.

RGB inage disnalysiti was applied to segmont the orea corresponding to the central axis and seects fif the case). The intensily components in RGB color space (ranging from 0 to 1 and their sum chual to 1.) were calcudaled: Hs indivaled in Eqs. [9..11.] and used for furthler segenentation as they atc aut intuenced by the lightress variability.

$$
\begin{aligned}
& \because \quad r(x, y)=i,\left[i_{r}+i_{h}+i_{h}\right) \\
& \operatorname{Ig}(x, y)-i_{x}\left(i,-i i_{g}+l_{b}\right) \\
& J(b), y)=i_{d} f\left(i_{r}+i_{2}+i_{b}\right) \\
& \text { : }
\end{aligned}
$$

: Here, $i_{r} i_{n}$, and $i_{\text {s. }}$ (rulyeging from 0 to 255 indepen-

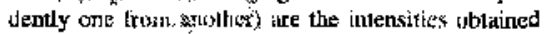
through red, grivis, ant bitue filters respetively. The intensity through the blue filter $\left(i_{b}\right)$ was selected to segment the whole tissue without peel, region of interest in RGB images (ROJ), whereas the red intorsity component $(I r)$ was selected to segmert the seeds and central axis region (SCR), as it enhances the contrast. The bistogram segmentation was doveloped at values of $i_{b}<255$ and $i_{r}<0.55$.

\section{Image Processing for Coronal MR lmages}

Consputation of Displacemsent during Lemon MNR. Diaring acquisition, time samples arc uoder continuउuy motion; therefore. there are view-to-view and intraview displacements. Such displacement; can te derived from thell speed $x$ the recovery time for each 
pulse sequence. When the conveyor is stable enough. this computation is relizble and can be directiy applied for phase shift correction (see below). However, whenever there is a significant lack of homogeneity for the conveyor speed (set with the elentronic controllet) there will be a significunt decrease in the performatace of motion correction.

To check the bomogeneity of the conteyor speed during type 2 image experitnents, navigitor (NAV) echoes aliong the motion beli direction were collected. These spectial echoes have no phase encoding so that the Fourier transformation will show profiles along the read encoding direcion. The sartiple motion leads to a spatial variation of the profiles from view to view within the field ofl view.

The most accurate technique to calculate toose dispiacements consists of interleaving the NAY between the views. However, timitations or the asequi" sition time do not allow such consideration. Thus, a reference displacement was calculated from a sequence of NAV echoes equivaterat to the type 2 inlage (i.e., same dats array size, pulse program, and gradient program) with to phase encoding gradient. The referesce sample was a water-filled cube phantom conveyed through the magnet: at the tested belt speeds.

Each NAV echo was Fourier transformed into profile. The modulus values were calculated arid noromalization wis' performed. Interpolation was used to ob. Iuin subpixel accuracy dispilucements $\%$ that the minimum dotecied displacement was 0.25 pixels. To. extract the view-to-view motion, the conckation atat least squssres algorithms were applied to the inferpolated profiles sets copsidering each point of then as a poirt in a space of cottinguous functions ( $2 I$ ) .

For each inlergellated set (64 profiles) collected at $50 \mathrm{~mm} / \mathrm{s}$ bele spocd, the profile in the middle of the $\mathrm{k}$-space was chosen as reference and the rest were stifted pixel by pixel (actraliy $0.25 \times 0.25$ pixels). At each Iteration step. tite distance between the shifted and the reference profile were calculated applying the distance functions for the corcelation method [1] and the leass square methixd [2] extracted from (2I):

$$
\begin{aligned}
& c(d)=-2 \cdot \sum_{x+w / ?}^{w / 2}\left[S_{d}(x)-s_{R}(x)\right] \cdot s_{f}(x) \\
& l(d)=\sum_{x=w+2}^{w / 2} 1
\end{aligned}
$$

where $s_{t}(x)$ is the profile shifted a displacernent $d$. $s_{n}(x)$ is the reference profile, and $w$ is the swept points within the navigator profiles (512 points).
The $d$ valse that gives the giningum distance is extratted for each nethod. Then, the distance between consecutive profiles $(\Delta x)$ is calculated and averaged for the whole profiles set being analy?tet. Slighr discontisuity problems arising from the thelt advance lead wo the aeed of individually adjust the reference displacexnent for each image. 'The extropy ninimizatixon (ly) was used as auto cutrection (this criterion will be described in the following section).

Motion Correction in Lemon Irages. According to the Fouries shift theorem (22), if a function $f(x)$ has Fourier transform $F(s)$ witen it is shitted, an amount $\Delta x$ the Firuier transform of $f(x-\Delta x), F^{\prime}(s)$, is $\left.e^{-i 2 \pi \Delta x} F f s\right\}$. This displacenent does not change the amplitade but rathes the plase of the conplex ptsints in the sampled echuses (20). Note that $F(s)$ is a corr plex number $(R+i Y)$ and so is $F^{\prime}(s)\left(R+i J^{\prime}\right)$ and that in order 10 ollestin the former the later is mulriplied by the inverse of the phase factor, $e^{-i 2 \pi \Delta x s}(23)$. The phase shift was calculated by Eq. [3] where the center of the echo is used as the reference point and the immediate carlier and latter points ate rotated negarively and positively respectively.

$\Delta$
$\therefore$
$\vdots$
$\vdots$

$$
\Delta \Phi_{\mathrm{x}}=2 \pi \cdot \Delta \mathrm{r} \cdot\left[s-\left(\begin{array}{c}
N_{2}-1 \\
2
\end{array}\right)\right], \frac{1}{N_{\lambda}}
$$

Herc, $N_{r}$ is the number of acquired points in the echo (i28 points), and $s$ is the point within the echo. For each phase-encixling step, $\Delta \Phi_{\mathrm{x}}$ is multiplied by the amresponding index (ranging from -31 to +32 ). As during the echo acquisition, the sample does not stop moritig, the phase shift the to the intraview notion had also to be bore in mind. It is calculared with the sampling time, i.e, dwell time $(20 \mu \mathrm{s})$ and the repetitorime time the fillowing equation:

$$
\Delta \Phi_{i v}=\frac{2 \pi \cdot \Delta r D w e l l T i n e}{T R} \cdot N_{x}
$$

Once the total phase shift, $A D$, at each point is calculated as the sum of $\Delta \boldsymbol{\Phi}_{x}$ and $\Delta \boldsymbol{\Phi}_{s+}$ the real ond imagintry components of the echoes cornplex points are cortected individually (20). The following expressions were applied:

$$
\begin{aligned}
& R_{\mathrm{r}} \cdots R^{\prime} \cos (\Delta \Phi)-f^{\prime} \cdot \sin (\Delta \Phi) \\
& \left.l_{c}=R^{\prime} \cdot \sin (\Delta \phi)\right)+f^{\prime} \cos (\Delta \phi)
\end{aligned}
$$

where $R^{\prime}$ and $V^{\prime}$ are the originally acquired real and inlaginaty components and $R_{c}$ and $t_{c}$ are the come- 


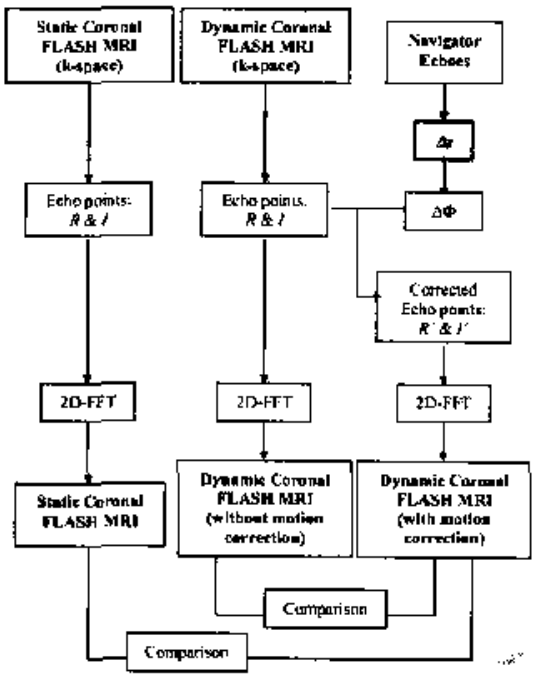

Figerv 3 Summary of motion comection prokedure for a)rinla] imases (type I images\}.

sporting correcied values. For the correction the mid. de echo was taken as reference so that the image would appear as static at that reference position $(20)$. The corrected data were zero filted to $128 \times 128$ and a two dimensional Fourier transform werc performed to obtain the inages (see Fig. 3).

As was previously stated the displacement between echoes, $\Delta x$, obtained from the. NAV echees bas to te adjusied for each inage The entropy

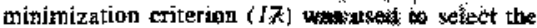
displacement that better corrected the jmage. Though the molion artifact is seen as ghosting and/or blurring of the isnage, the entropy minitsization increases the number of durk pixels in the irnage favoring high conttast (17) and facilitating the correction adjustment. As the belt speed is not absidulely constart. to find the displacement that mininized the entropy of the image, the $\Delta x$ obtwined with the phaniom was nutimatically ranged from the calculated value minus 0.03 to the calculated value plus 0.03 varying 0.01 each step. This range was selected after computing the average variation of $\Delta x$ between homologous experiments. The eatropy was calculated at each step with the following expression:

$$
E=-\sum_{j=1}^{S} \frac{B_{j}}{B_{\operatorname{axa}}} \ln \left(\begin{array}{c}
B_{j} \\
B_{\max }
\end{array}\right)
$$

where $s$ is the number of inuge pixels $(128 \times 1.28), b_{j}$ (gixed "brightress") is the modulus of the complex value of the $i^{\text {it }}$ image pixel and $B_{\max }$ (8), which remains invarient under translationd motion, is the latgest possible pixel brightness obtained if all the image energy were in obe pixal $(17)$.

$$
B_{\max }=\sqrt{\sum_{i=1}^{r} B_{j}^{2}}
$$

The $\Delta x$ value that gave the minimum $E$ was selected to cortect the motion and thes to obtain the consesponding image.

Qually Evaluation of Lemon limages after Afotion Correction The irrages tobtained under motion conditions from the two different slice positions (i.e., $x y$ plane and $x z$ planc) were evaluated to estatilish which kind offered the best quality for the subseciutenl seg. nentalion. In stalic inages of citsus with seeds. the fistograti of the selected RO1 shows clearly two popsulatious of pixels. those corresponding to the peed, seeds, fots central axis region (lower intensity signal) atdo those of the Alesh region (higher intensily signal), When itrouge is blorted, peaks are broadiened and even werlap. It leads to a variation in the lower petcentiles of the histograms. An analysis of viriance (ANOVA) a! 1 to and $5 \%$ stgniticance levels wiss anplied ox the 10 quartile (as il mainly reprenerts the pixels belonging to seed) of the ROls in the MR images under static and tynamic conditions. This study was developed to asiess diflexterces thetween the histograns of

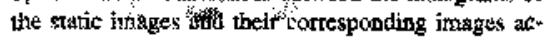
quired under dynamic conditions.

\section{RESULTS AND DISCUSSION}

Oranges sorted as seed-tentaining with MRl were confirmed sis so by destructive internal inspection. For all oranges, the number of seeds ranged fron 0 to 19 within the shole fruit and from if to 10 within the slice imaged by MRI. When the equarorial section and the MR images were visually compared, the correspondence between the seed location and the low signal regions in these images could be revealed. RGB segmentation of fraits cross-section also tepealed such correspondence (Figs. 4 and 5). Table 1 


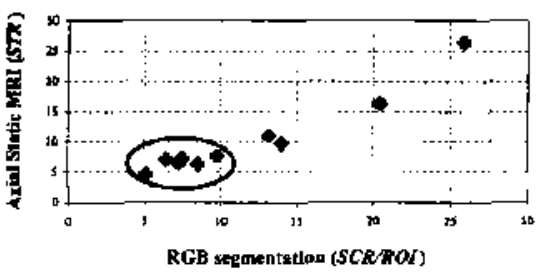

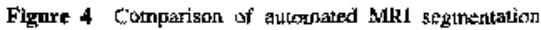
(noudestructive) under static condlitions and RCSB segmertation (destructive). Values o[ sectlexs oranges and oranges contatring noe seed acte within the ellips.

shows the number of seets within the itnaged slice and the ratio SCR/ROI obtained with RGB segmenthation.

\section{Seed Detection in Axlal MR lmages}

Axial images under twotion conditions showed blurring due to the supenimposition of signal arising from $s \%$ new tissue reaching the spatial position of the selectext field of view during the acquisition tins. As expected, the higher belt speed and/or the lower acquisitinn matrix size the higher the problens conceraing blurring artifacts. However, the contrast between the flesh signal and the seeds and central axis tissue was enough to allow a reliable segrentation when same: ples were conveyed through the magnet at $50 \mathrm{~nm} / \mathrm{s}$ belt speed with $128 \times 6$ a acquisition ontrix size. Figure 6 shows some examples of secdifiter oranges and oranoes containing secds.

The algoritbm developed to extract mathenatieal features tor seed detection was applied to the static

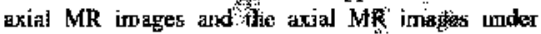
motikn conditions. Thesc featuses we lincarly cotrelated to the $\$ C R$ ROI ratis extracted from the RGB images (see Tatble 2).

As showi in Tuble 2, most of the MRI feansres show bigh correlation coefficients with the RGB reference measurcenent. The ratio of typointense signal

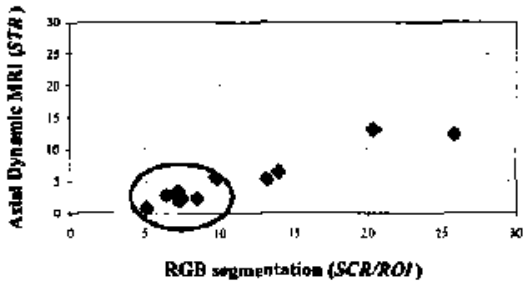

Figure $\$$ Compurisom of aulorated MRd seguentation (nominstructive) under dynamit conditions and RGB seg" mentation (destructive). Valyes of seedless orages and orutges containing one wed ane within the ellipse.

(HIR) lissue with regand to the region of interest (STR) and the perimeter (P) of the HIR are the best correlatcd. The high $r$ values suggest that the segmentalion in MR images is reliable. This result is consistent under salac and dynamic conditions, so these parameters were selected to develop further analysis.

The STR and $\mathrm{P}$ values corresponding to these repetitions per orange were considered as individual samples and used for ussupervised orange clustering. This antlysis grouped the oranges into Iwo mairt clusters, containing oranges wibl 0 or 1 seed (cluster 1) and fyxits containing more than 1 seed (claster 2), ranging frim 2 to 10 . Although it is possible to subdivide the cluster with high seed-content, it is dificult to differentiate geedless (ranges from those with a single seed because of the variabilty in site of the central axis areil (see Figs, 4 and 5), The cluster analysis provides she mean and the standird deviation (SD) for eacli cluster and the ratio between the averaged (averaged SD) and the range (cluster 2 ynean inosus cluster I meario). These dato are summasimod in Table 3 ."

Table 3 showsithe results of the clustering proce. dure corresfonding to feutumes from axial static $M A R$ images compared with those of dymamic axial MR images. The average difference botwcen clusters is always lower for the dynamic MR images than for

Table I Namber of Suedin within the Inaged slice and Charactortzation of RGB segmentablon

\begin{tabular}{|c|c|c|c|c|c|c|c|c|c|c|c|}
\hline \multirow[b]{2}{*}{$\left(\mathrm{ACR}^{*} / \mathrm{ROI}^{\mathrm{t}}\right)$} & \multicolumn{3}{|c|}{$\begin{array}{c}\text { Oranges withour } \\
\text { Secdy }\end{array}$} & \multicolumn{8}{|c|}{ Oranges with Seads } \\
\hline & 1 & 2 & 3 & 4 & 5 & 6 & 7 & 8 & 9 & 20 & 11 \\
\hline $\begin{array}{l}\text { Nutrityer of seads } \\
\text { SCR } /\left.R^{*}\right|^{b}(\phi)\end{array}$ & $\begin{array}{l}0 \\
6.4\end{array}$ & $\begin{array}{l}0 \\
7.2\end{array}$ & $\begin{array}{l}0 \\
7.5\end{array}$ & $\begin{array}{l}1 \\
8.5\end{array}$ & $\begin{array}{l}1 \\
9.8\end{array}$ & $\begin{array}{l}1 \\
7.3\end{array}$ & $\begin{array}{l}\text { I } \\
6,3\end{array}$ & $\begin{array}{c}2 \\
13.2\end{array}$ & $\begin{array}{c}3 \\
\mathrm{~J} 4.0\end{array}$ & $\begin{array}{c}7 \\
20.4\end{array}$ & $\begin{array}{l}10 \\
25.9\end{array}$ \\
\hline
\end{tabular}

- SCQ = sted and curneal uxis reyion in RCBB images (number of pirels).

'ROA =: region of interest; enaine tissue area in RG̈ images (number of pixels). 
Belt speed: $0 \mathrm{~mm} / \mathrm{s}$
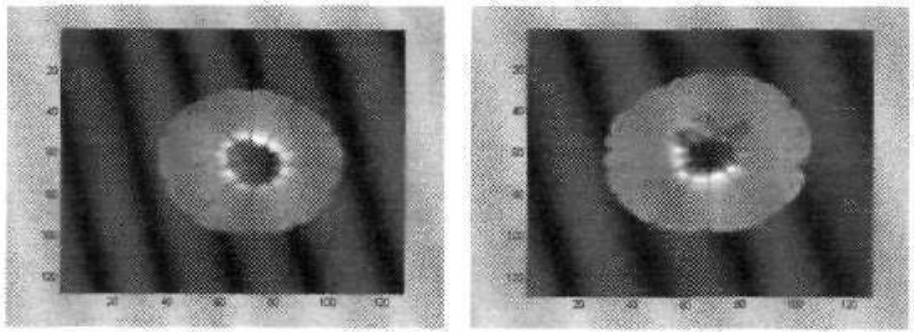

Belt speed: $54 \mathrm{~mm} / \mathrm{s}$
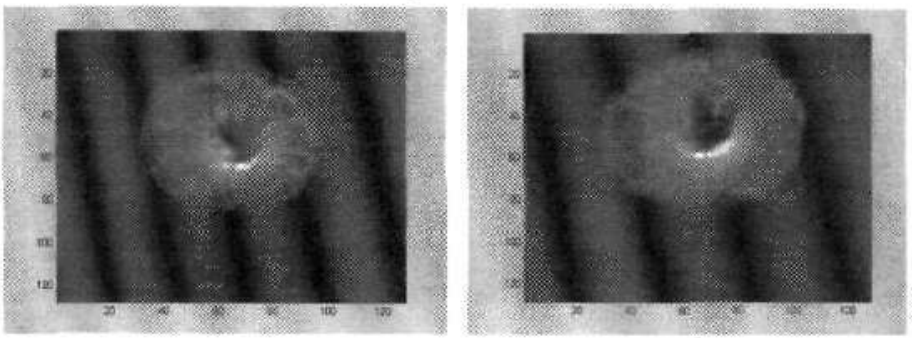

Belt speed: $90 \mathrm{~mm} / \mathrm{s}$
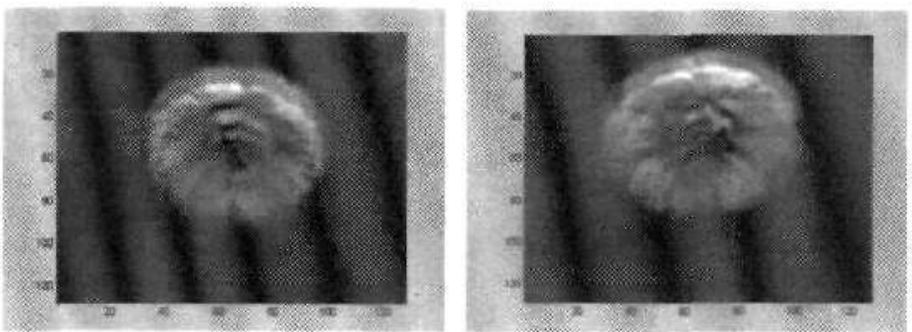

Figure 6 MRI examples (type 1) of seedless oranges and oranges containing seeds at different belt speeds.

static MR images as a result of the superimposition of signal from the different tissues measured during motion. In cluster 1 ( 0 or 1 seed), the SD does not vary significantly; in cluster 2 (2-10 seeds), the decrement in the SD under dynamic conditions shows that differences between oranges became less clear as STR and $\mathrm{P}$ values are more homogeneous within the clus- ter. The reduction in SD/range ratio suggests that distance between clusters also decreases under $d y-$ namic conditions as a result of blurring. When STR computed from MR images is compared with that computed from RGB images (features not shown), the major similarities are seen under static conditions, as the image quality is higher (see Fig. 4). 
Yabje 2 Unear Correlation Coefflcient between Reference Measurements (SCR/ROI at RGB ImBge) and MRI Features

Eimear Cortelation Coefficienl MRI-RGH ic

\begin{tabular}{|c|c|c|c|c|c|c|c|}
\hline & STR & $p$ & $4 \pi H I R / P^{2}$ & NR $>\mathbf{R}_{\text {makk }}$ & $\mathbf{S}>\mathbf{R}_{\mathrm{maxx}}$ & $\mathrm{NR}>\mathrm{R}_{\mathrm{mem}}$ & $S>R_{\operatorname{mam}}$ \\
\hline Staric axiaI MRI & 0.96 & 0.97 & -6.82 & 0.63 & 0.54 & 0.9 & osy \\
\hline Dynamíc axial MRI & 0.95 & 0.97 & 0.62 & $0.7 \%$ & 0.81 & 0.82 & 0,82 \\
\hline
\end{tabular}

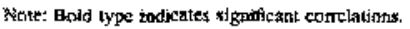

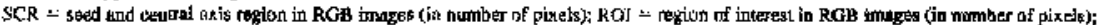

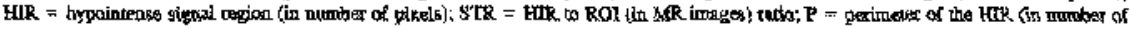

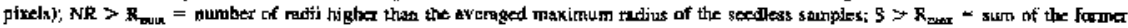

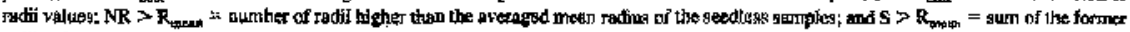
Ia्Atii Yalues.

To study the robisiness of mathentatical features. the repeatability error of the STR and P was com puted. Tabie 4 shows that mese parameters are less corsistent when firuit is conveying through the magnet as the averager SD has higher values than those atder static conditions. The repentability enot is observed to inctease when the number of seeds becomes greater (cluster 2).

These resutst show that STR is the best MRI feauare for seod characterization as it leads to a highs distatice between clusters ind has betser repeatiability results.

As expected, the better the image quallity the better the repeatability and discrimination. Thise, for application purposes, it is necessary to reduce the blutaing in the images by acquiring then in such a way thas the imaged tissue does not change along the axquisition duration to ensure that there is no signal superimpos.

Table 3 Statistics of Clusters cenerated with ARI

\begin{tabular}{|c|c|c|c|c|}
\hline & Static C & oditions & 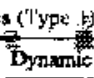 & Conditions \\
\hline & Cluster 1 & Clyster 2 & CFustcr 1 & Cluster 2 \\
\hline STR (Sh) & & & & \\
\hline Misen & 6.6 & 16 & 2.8 & 9.7 \\
\hline SD & 0.9 & 6.9 & 1.4 & 3.8 \\
\hline $\begin{array}{c}\text { SDrunge } \\
\left(\phi_{0}\right)\end{array}$ & & & & \\
\hline $\begin{array}{r}P \text { (no. of } \\
\text { pixels) }\end{array}$ & & & & \\
\hline Mcan & 70 & $20 \theta$ & 45 & 107 \\
\hline SI) & 14 & 91.4 & 15.6 & 9.2 \\
\hline $\begin{array}{c}\text { SDrivge } \\
\text { (思) }\end{array}$ & 3 & & & \\
\hline
\end{tabular}

SD $>$ standard devintion; SIR = smed tissue to rekiun of interess natio: $p$.. seed tissue perimeler. sition, i.e. selecting the slice to image laying on the $x z$ plane (coronal image). Therefore, it was necessary to develop an âlgorithrn aimed at correcting the phase shif in the $k$-sprace hnes caused ty the change in the slice location within the FOV during acquisition. This grocediture had to be lime afficienl as well.

Relevant recent work has been done in fruit-grarling lines toward ensuring fruit oricntation, which is a misjor restriction for some innovative guatity-sunsing teshniques. Therefore, state of the art can be used for large-scalc applications $(24,25)$.

\section{Motion Correction in Coronal MR images for Seed Datectlos improvement}

The NAV echo's of the phantony verified that the conveyor used for the experiments presents high stability for bell speed, allowing a suecessful determination of the displacernent ( $\Delta t)$ during signal acquisjtion. However, comfrollet speed was revezled oo be $54+0.8 \mathrm{~min} / \mathrm{s}$ and $90 \pm .3 .9 \mathrm{~mm} / \mathrm{s}$ instead of 50 and

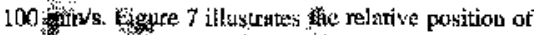

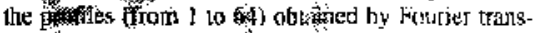
forming the NAV echor acquthed at $54 \mathrm{~mm} / \mathrm{s}$ bell speed. The onrretation irad the least square methods

Table 4 Repeatabiltty Error of the Computed MRI Features under Static and Dynarnic Axial sequences (50 $\mathrm{mm} / \mathrm{s}$ belt speed)

\begin{tabular}{|c|c|c|c|c|}
\hline & \multicolumn{4}{|c|}{ Axial lmayes (Typ 1$\}$} \\
\hline & \multicolumn{2}{|c|}{ Static Couditions } & \multicolumn{2}{|c|}{ Dynamic Conditions } \\
\hline & Cluster 1 & Cluster 2 & Cluster 1 & Clustic 2 \\
\hline $\operatorname{STR}\left(\mathrm{S}_{\mathrm{A}}\right)$ & 0.1 & 0.3 & 0.3 & 1 \\
\hline $\begin{array}{r}P \text { (no. of } \\
\text { pixcels) }\end{array}$ & 1 & 3 & 6 & 8 \\
\hline
\end{tabular}

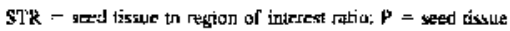
perimeter. 


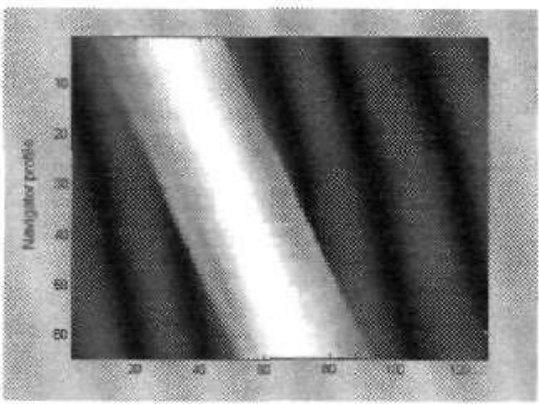

Figure 7 Navigator echoes (NAV) used for type 2 images to address the relative position of the profiles obtained for a phantom during motion at $54 \mathrm{~mm} / \mathrm{s}$

both computed the same displacement between consecutive profiles in all the studied cases.

The average displacements between consecutive profiles were obtained for type 2 images at $54 \mathrm{~mm} / \mathrm{s}$ as 0.70 pixels and at $90 \mathrm{~mm} / \mathrm{s}$ as 1.15 pixels. The repeatability error was 0.01 pixels and 0.05 pixels respectively. Note that subpixel displacement can be addressed because of interpolation and was used for accurate phase shift correction.

The reference displacenient was adjusted for each reconstructed $128 \times 128$ matrix size images. Figuse 8 illustrates an example of motion correction. The result of the correction is qualitatively impressive, though some objective measures of the quality increase were performed.
Figure 9 shows the histograms of axial and coronal MR images: static axial (up/left), dynamic axial (up/ right), static coronal (down/left), and dynamic coronal with motion correction (down/right). Visually, it can be appreciated that there is a reliable correspondence between histograms of coronal images. An ANOVA (Table 5) shows that there is a significant difference in the mean intensity signal value at the $1 \%$ and $5 \%$ significance levels for both sorts of images. However, lower quartile is invariant in the coronal images with motion correction with regard to static coronal images, wherwas it is significantly different between static and dynamic axial images.

\section{CONCLUSIONS}

FLASH imaging sequence is a suitable technique for the online detection of seeds in citrus. Encouraging results have been achieved when oranges were axially imaged under static conditions and while moving at $54 \mathrm{~mm} / \mathrm{s}$ belt speed. At higher speeds, loss in quality of axial images does not allow seed identification.

Arl algorithm has been successfully developed for the discrimination of oranges with more than one seed. However, due to the variability in the thickness and the geometry of the central axis, it is not possible to distinguish seedless oranges from single-seed fruits-a major criterion for quality and prize devaluation.

The percentage of hypointense tíssue in relation to the whole tissue (STR) is the most reliable feature for seed ideatification. These results are greatly influenced by the imsge quality. As a result, it is impera-

\section{Without motion correction}

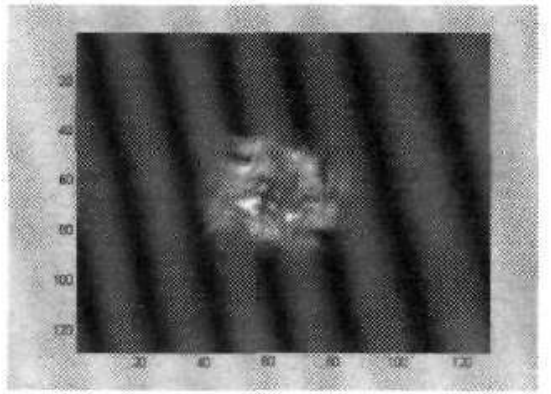

\section{With motion correction}

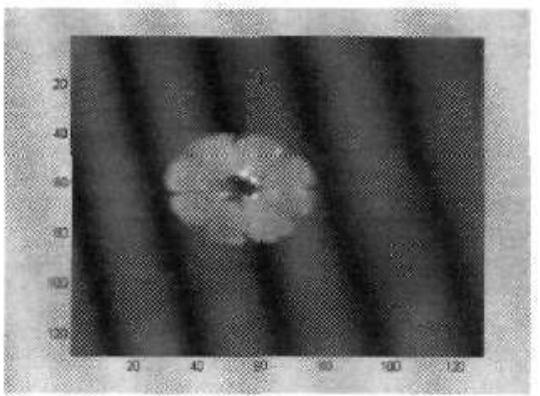

Figure 8 Examples of coronal MR images without and with motion correction (left and right respectively,) 
HISTOGRAMS of Axial MR images (Type-1)

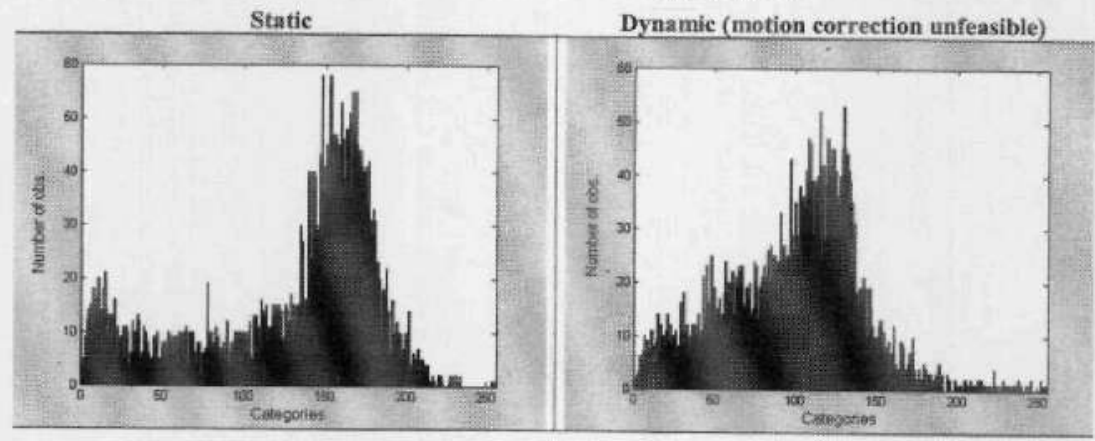

HISTOGRAMS of Coronal MR images (Type-2)

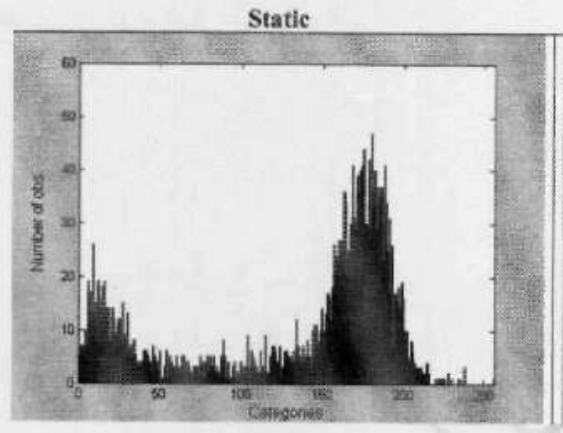

Dynamic (with motion correction)

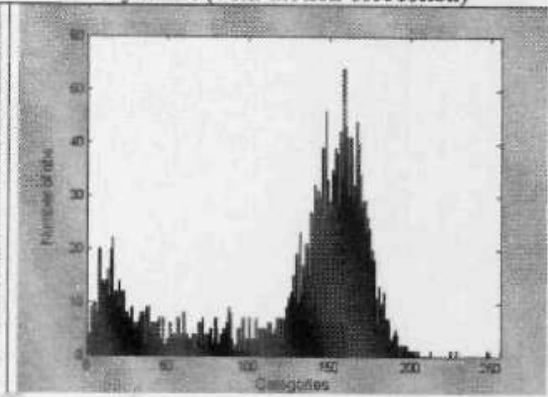

Figure 9 Histogram examples of MR images. Upper line corresponds to the histogram of an axial image under static (left) and dynamic (right) conditions. Lower line corresponds to the histogram of a coronal image under stafic (left) and dynamic conditions ( $54 \mathrm{~mm} / \mathrm{s}$ belt speed) with motion correction (right).

Table 5 Results of ANOVA (1\% and 5\% Significance Level) for the Histogram Features

\begin{tabular}{lcccc}
\hline & \multicolumn{5}{c}{ Axial Images (Type 1) } \\
\cline { 2 - 5 } & Static & Dynamic & F & $p$ \\
\hline Mean & $9.56 \mathrm{E}+08$ & $6.80 \mathrm{E}+08$ & 41.415 & $\mathrm{k*}$ \\
Lower quartile & $8.70 \mathrm{E}+08$ & $5.24 \mathrm{E}+08$ & 34.9096 & $* 8$ \\
\hline \multicolumn{4}{c}{ Coronal Images (Type 2) } \\
\cline { 2 - 5 } & Static & Dynamic & F & $p$ \\
\hline Mean & $1.48 \mathrm{E}+06$ & $1.32 \mathrm{E}+06$ & 20.348 & *** \\
Lower quartile & $1.23 \mathrm{E}+06$ & $1.16 \mathrm{E}+06$ & 0.5253 & n.s. \\
\hline
\end{tabular}

$*=$ significance at $1 \%$; n.s. $=$ no significance. tive to reduce the motion artifacts displayed in the images.

The acquisition of coronal images and the development of a low time-consuming motion correction procedure is the first step in the achievement of highquality online MR images and will be used in further research for the identification of single-seed fruits.

\section{ACKNOWLEDGMENTS}

We thank the Spanish Science and Technology Ministry for financing the project OPTIFRUT (AGL. 2001-3792-C02-01). 